\title{
Cation Solvation and Physicochemical Properties of Ca Battery Electrolytes
}

\author{
J. D. Forero-Saboya, ${ }^{\dagger}$ E. Marchante, ${ }^{\dagger}$ R. B. Araujo, ${ }^{\ddagger}$ D. Monti, ${ }^{\dagger}$ P. Johansson, ${ }^{*},+\S \odot$ \\ and A. Ponrouch ${ }^{*}, \dagger, \S_{0}$ \\ ${ }^{\dagger}$ Institut de Ciència de Materials de Barcelona (ICMAB-CSIC), Campus UAB, 08193 Bellaterra, Catalonia, Spain \\ ${ }^{\ddagger}$ Department of Applied Physics, Chalmers University of Technology, SE-412 96 Göteborg, Sweden \\ ${ }^{\S}$ ALISTORE-European Research Institute, CNRS FR 3104, Hub de l’Energie, 15 Rue Baudelocque, 80039 Amiens, France
}

Supporting Information

\begin{abstract}
Divalent-cation-based batteries are being considered as potential high energy density storage devices. The optimization of electrolytes for these technologies is, however, still largely lacking. Recent demonstration of the feasibility of $\mathrm{Ca}$ and $\mathrm{Mg}$ plating and stripping in the presence of a passivation layer or an artificial interphase has paved the way for more diverse electrolyte formulations. Here, we exhaustively evaluate several Ca-based electrolytes with different salts, solvents, and concentrations, via measuring physicochemical
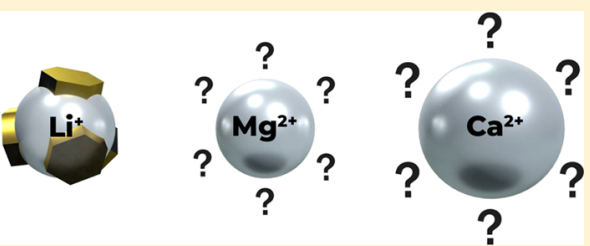
properties and using vibrational spectroscopy. Some comparisons with $\mathrm{Mg}$ - and Li-based electrolytes are made to highlight the unique properties of the $\mathrm{Ca}^{2+}$ cation. The Ca-salt solubility is found to be a major issue, calling for development of new highly dissociative salts. Nonetheless, reasonable salt solubility and dissociation are achieved using bis(trifluoromethanesulfonyl)imide (TFSI), $\mathrm{BF}_{4}$, and triflate anion based electrolytes and high-permittivity solvents, such as ethylene carbonate (EC), propylene carbonate (PC), $\gamma$-butyrolactone (gBL), and $N, N$-dimethylformamide (DMF). The local $\mathrm{Ca}^{2+}$ coordination is concentrationdependent and rather complex, possibly involving bidentate coordination and participation of the nitrogen atom of DMF. The ionicity and the degree of ion-pair formation are both investigated and found to be strongly dependent on the nature of the cation, solvent donicity, and salt concentration. The large ion-ion interaction energies of the contact ion pairs, confirmed by density functional theory (DFT) calculations, are expected to play a major role in the interfacial processes, and thus, we here provide electrolyte design strategies to engineer the cation solvation and possibly improve the power performance of divalent battery systems.
\end{abstract}

\section{INTRODUCTION}

Achieving sustainable and affordable energy sources and storage is one of the major challenges of our modern society-not the least to attack climate change and oil dependency. Considering only the transportation contribution, more than 1.2 billion vehicles are currently at use all around the world, and less than $0.2 \%$ are electric. While Li-based battery technologies undoubtedly will power more and more electric vehicles (EVs) in the next 5-10 years, the controversial debate on sustainability and production/extraction costs of lithium cannot be ignored. ${ }^{1,2}$ The development of alternative battery chemistries based on abundant elements is thus urged for to accommodate a significant growth of the EV market. Calcium- and magnesium-based batteries are interesting candidates as they hold promise for safe use of metal anodes, thus potentially presenting high energy densities and low cost. Indeed, $\mathrm{Ca}$ and $\mathrm{Mg}$ electrodes have theoretical specific capacities of 1340 and $2000 \mathrm{mAh} \mathrm{g}^{-1}$, standard redox potentials of -2.76 and $-2.38 \mathrm{~V}$ vs the standard hydrogen electrode (SHE), and are the fifth and eighth most abundant elements on the Earth's crust, respectively., 3,4

A myriad of Ca-based battery concepts have been developed since the first report of calcium as an electroactive element in
$1964 .{ }^{5}$ Mostly, thermal batteries, using electrolytes with very high melting points, and the calcium equivalent to the commercial $\mathrm{Li}$ thionyl chloride $\left(\mathrm{Li}-\mathrm{SOCl}_{2}\right)$ batteries were developed. ${ }^{6}$ However, in contrast to $\mathrm{Mg}$, electrodeposition of calcium has for long been elusive and only primary cells were achieved. The lack of calcium plating upon cell reversal was even considered as a safety advantage for the $\mathrm{Ca}-\mathrm{SOCl}_{2}$ cells as compared with its $\mathrm{Li}$ analogue.

Moving to room-temperature and liquid electrolytes, no Ca equivalents to $\mathrm{Mg}$-based Grignard reagent electrolytes (allowing for $\mathrm{Mg}$ plating and stripping) are available. ${ }^{8}$ Seminal studies by Aurbach et al. using conventional aprotic organic electrolytes similar to those used for lithium-ion batteries (LIBs) allowed them to conclude that the electrochemical behavior of Ca metal anodes is surface-film controlled, as is the case for $\mathrm{Mg}^{9,10}$ The lack of divalent cation permeability of the formed passivation layer was suggested to be the origin of the impossibility to electrodeposit calcium or magnesium. While the electrolyte remains a major bottleneck for any divalent-

Received: July 31, 2019

Revised: November 6, 2019

Published: November 14, 2019 

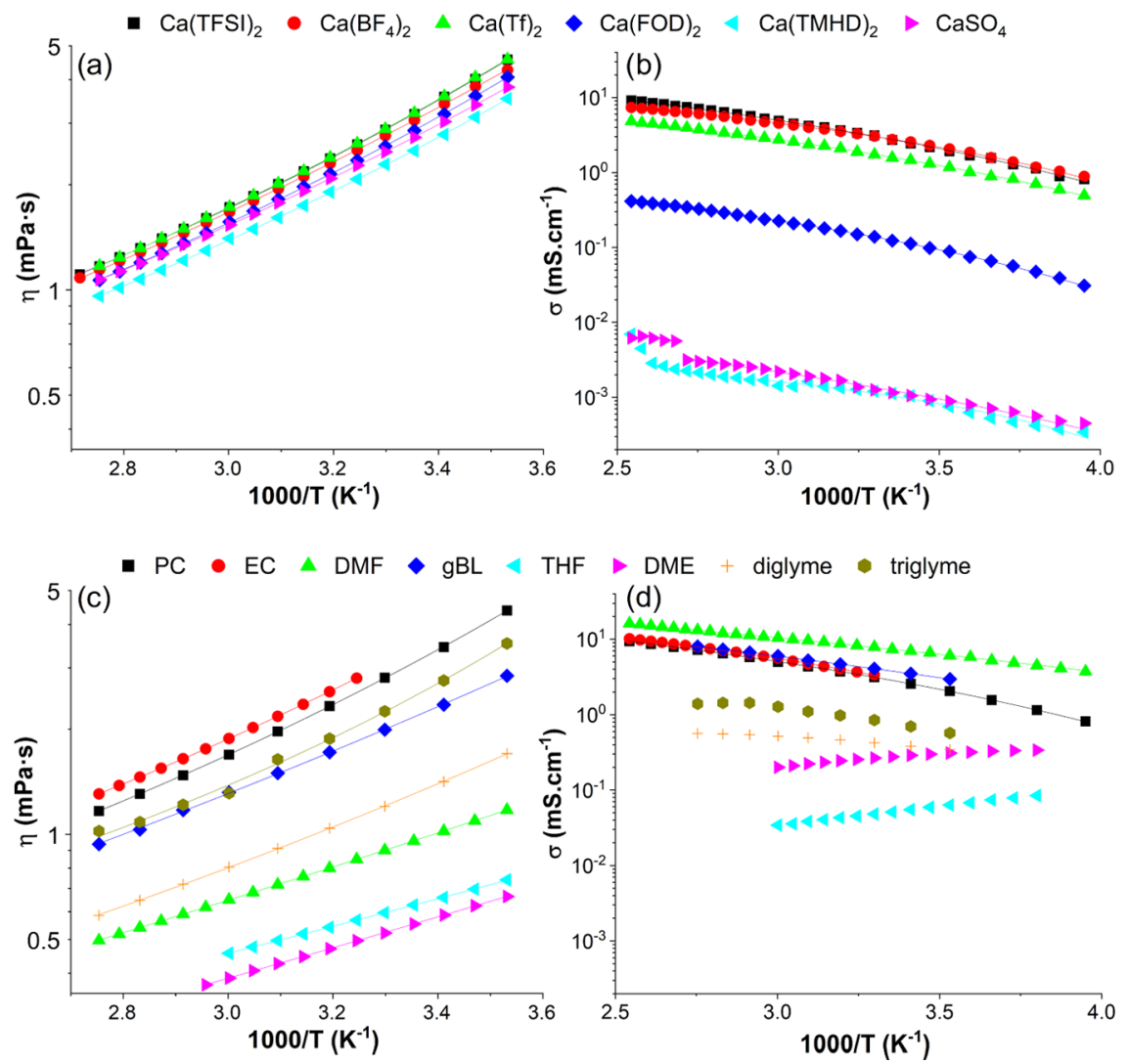

Figure 1. Physical properties of calcium-based electrolytes. Arrhenius plots for (a) viscosity and (b) conductivity of $0.1 \mathrm{M}$ calcium salt in PC. Arrhenius plots for (c) viscosity and (d) conductivity for $0.1 \mathrm{M} \mathrm{Ca}(\mathrm{TFSI})_{2}$ in several solvents. Solid lines represent the Vogel-Tammann-Fulcher (VTF) fits.

cation-based batteries and most research studies so far have focused on electrolytes for which no passivation layers are formed (mostly based on ether solvents), ${ }^{8-10}$ recent demonstrations of $\mathrm{Ca}$ and $\mathrm{Mg}$ plating and stripping in the presence of a passivation layer or an artificial interphase ${ }^{11-13}$ have paved the way for evaluation of new electrolyte formulations by allowing decoupling of interfacial and electrolyte requirements. The present study, thus, focuses on important parameters in the design of new electrolytes, ${ }^{14,15}$ such as cation mobility and desolvation energies, broadening the choices of electrolyte component candidate salts and solvents, potentially leading to formation of better-performing passivation layers.

As compared to $\mathrm{Li}^{+}$and $\mathrm{Na}^{+}$conducting electrolytes, divalent-cation-based electrolytes have a stronger tendency of ion-pair formation ${ }^{16}$ and larger cation desolvation energies. ${ }^{17}$ In addition, as the $\mathrm{Li}^{+}$and $\mathrm{Na}^{+}$mobilities are significantly lower than those of the anions ${ }^{1}$ and the desolvation energy plays a major role in the kinetics of $\mathrm{Li}^{+}$insertion into graphite, ${ }^{18-21}$ it can be expected that the power performance of any divalent-cation-based batteries will also depend greatly on the nature of the cation solvation shell. Here, we systematically investigate calcium-based electrolytes and report on the relationship between the cation solvation, coordination number and ion pairing, and physicochemical properties, such as ion conductivity and viscosity for different salts and concentrations and organic solvents. Some parallels are drawn with $\mathrm{Li}$ and $\mathrm{Mg}$ systems allowing for a better understanding of the strategies to optimize divalent cation mobility and desolvation energy.

\section{EXPERIMENTAL SECTION}

Materials. The solvents used were propylene carbonate (PC, Aldrich, anhydrous, 99.7\%), ethylene carbonate (EC, Aldrich, anhydrous, 99.0\%), N,N-dimethylformamide (DMF, Alfa Aesar, 99.7\%), $\gamma$-butyrolactone (gBL, Aldrich, anhydrous, 99.0\%), tetrahydrofuran (THF, Aldrich, anhydrous, 99.9\%), 1,2-dimethoxyethane (DME, Aldrich, anhydrous, 99.5\%), diethyleneglycol dimethyl ether (diglyme, Aldrich, 99.0\%), triethyleneglycol dimethyl ether (triglyme, Aldrich, 99.0\%), and fluoroethylene carbonate (FEC, Aldrich, 99\%).

The commercially available calcium salts used were calcium bis(trifluoromethanesulfonyl)imide $\left(\mathrm{Ca}(\mathrm{TFSI})_{2}\right.$, Solvionic, 99.5\%), calcium tetrafluoroborate $\left(\mathrm{Ca}\left(\mathrm{BF}_{4}\right)_{2}\right.$, Alfa Aesar, hydrated), calcium trifluoromethanesulfonate $\left(\mathrm{Ca}(\mathrm{Tf})_{2}\right.$, Sigma-Aldrich, 99.9\%), calcium sulfate $\left(\mathrm{CaSO}_{4}\right.$, Sigma-Aldrich, $99.99 \%)$, calcium bis $(6,6,7,7,8,8,8$-heptafluoro-2,2-dimethyl3,5-octanedionate) ( $\mathrm{Ca}(\mathrm{FOD})_{2}$, Sigma-Aldrich, >99.9\%), and calcium bis(2,2,6,6-tetramethyl-3,5-heptanedionate) (Ca$(\mathrm{TMHD})_{2}$, Sigma-Aldrich). LiTFSI (Solvionic, 99.9\%) and $\mathrm{Mg}(\mathrm{TFSI})_{2}$ (Solvionic, 99.5\%) were also used to create reference electrolyte systems. All salts and solvents were kept and used under a dry atmosphere $\left(<1 \mathrm{ppm} \mathrm{O}_{2}\right.$ and $\left.\mathrm{H}_{2} \mathrm{O}\right)$ in an argon-filled Jacomex glovebox at $25{ }^{\circ} \mathrm{C}$.

Electrolytes. First, two families of Ca-based electrolytes were made by dissolving (i) six different Ca-salts in PC at a concentration of $0.1 \mathrm{M}$ and (ii) $0.1 \mathrm{M} \mathrm{Ca}(\mathrm{TFSI})_{2}$ in eight different solvents. Subsequently, a third family was evaluated for the best solvent and 0.1-1.5 M Ca(TFSI $)_{2}$, and this was also further compared with LiTFSI- and $\mathrm{Mg}(\mathrm{TFSI})_{2}$-based electrolytes. All electrolytes were prepared under a dry 

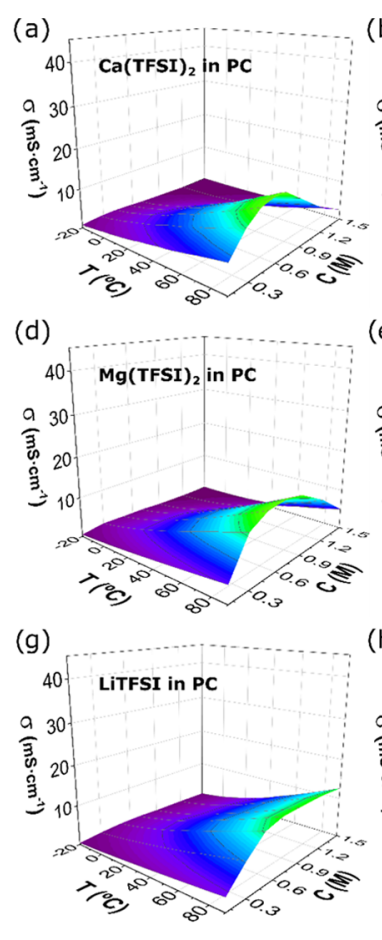

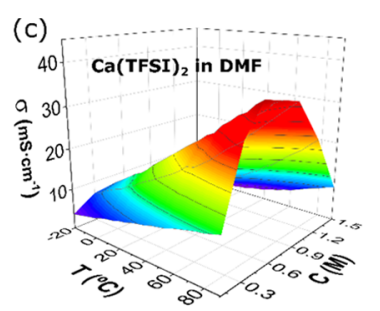

(e)
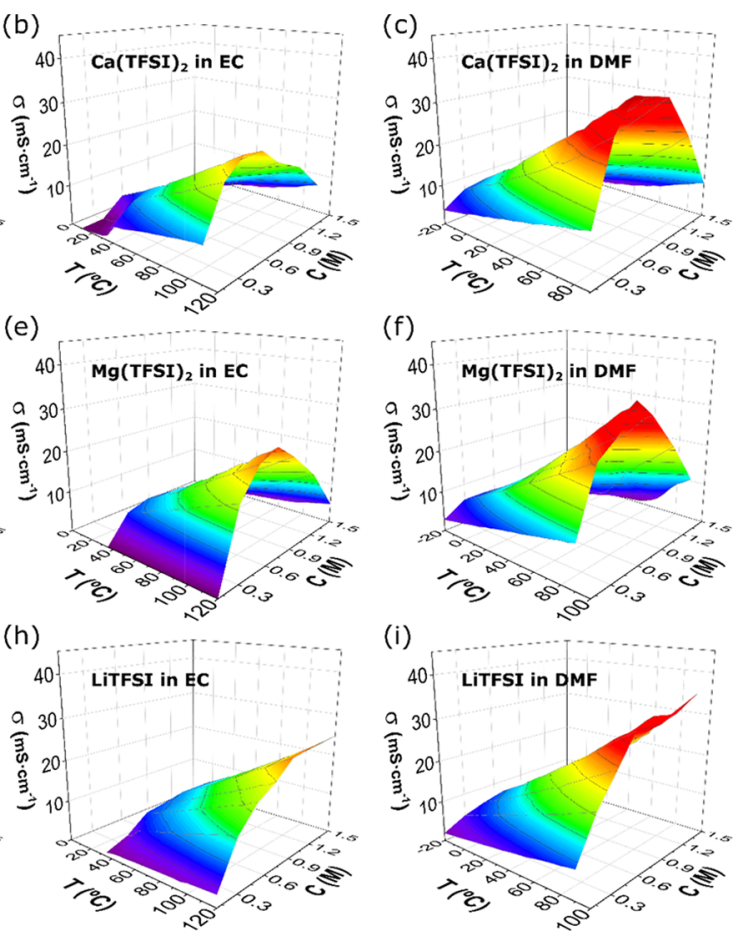

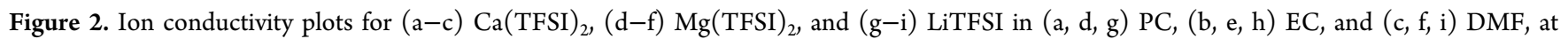
different concentrations and temperatures.

atmosphere in the glovebox and remained there until analysis. Molecular sieves (Alfa Aesar, $3 \AA$ A) were used as drying agents for each electrolyte. Prior to any characterization, the water contents were measured using an 899 Karl Fisher Coulometer (Metrohm), resulting in $<30 \mathrm{ppm}$ for all electrolytes.

Experimental Methods. Ion conductivity measurements were performed using a FRA-based Multiplexed Conductivity Meter MCM 10 (BioLogic Science Instruments) from -20 to $+120{ }^{\circ} \mathrm{C}\left(10{ }^{\circ} \mathrm{C}\right.$ steps with 20 min equilibration time).

Viscosity and density measurements were carried out from +10 to $+90{ }^{\circ} \mathrm{C}$ using a rolling-ball viscometer (Lovis $2000 \mathrm{M}$ / $\mathrm{ME}$, Anton Parr). The cell temperature was regulated within $\pm 0.02{ }^{\circ} \mathrm{C}$. Ultrapure water was used to calibrate the viscometer and densitometer. The uncertainties of the density and viscosity measurements were less than $5 \times 10^{-5} \mathrm{~g} \mathrm{~cm}^{-3}$ and $0.5 \%$, respectively.

Fourier transform infrared (FT-IR) spectroscopy was carried out using a Jasco FT/IR-4700 Spectrometer with the universal ATR Pro One accessory (equipped with a diamond crystal) for the range $500-4000 \mathrm{~cm}^{-1}$ at a resolution of $2 \mathrm{~cm}^{-1}$.

Raman spectra were recorded using a Bruker MultiRAM FTRaman spectrometer with a spectral resolution of $2 \mathrm{~cm}^{-1}$ using a Nd:YAG laser $(1064 \mathrm{~nm}, 500 \mathrm{~mW})$ as the excitation source. Data were typically averaged over 500 scans and recorded at 40 ${ }^{\circ} \mathrm{C}$ for the carbonate-based electrolytes and $25{ }^{\circ} \mathrm{C}$ for the DMF-based electrolytes. All bands in the resulting spectra were fitted as Voigt functions, typically with a unity Gaussian/ Lorentzian mix by width, using Origin Software.

Computational Details. The Raman activities of the complexes $\left[\mathrm{Ca}(\mathrm{DMF})_{6}\right]^{2+},\left[\mathrm{Ca}(\mathrm{PC})_{6}\right]^{2+}$, and $\left[\mathrm{Ca}(\mathrm{FEC})_{6}\right]^{2+}$ were obtained by first creating the initial structures by employing the minima hopping global optimization algorithm $(\mathrm{MH})$ as implemented in the Atomistic Simulation Environment (ASE) coupled with TURBOMOLE. ${ }^{22-24}$ This method carries out short ab initio molecular dynamics (AIMD) and local optimizations to explore the energy landscape where the temperature is used to escape any local minima. The AIMD runs were performed in the microcanonical ensemble with a time step of $1 \mathrm{fs}$. The BP86 functional was employed together with a SVP basis set as implemented in TURBOMOLE. ${ }^{25,26}$ The $\mathrm{MH}$ algorithm started at $300 \mathrm{~K}$ and an initial energy threshold of $48 \mathrm{~kJ} \mathrm{~mol}^{-1}$. The subsequent calculations of gasphase geometries and Raman activities for the most stable structures used the M06-2X functional and the 6-31G** basis set as implemented in the Jaguar package. ${ }^{27-31}$ All obtained structures appear to be minima, with no imaginary vibrational frequencies.

\section{RESULTS AND DISCUSSION}

Viscosity and Ion Conductivity. To separate out the relative influence of the solvent and the nature and concentration of the salt, two different families of electrolytes were made. First, the six different Ca-salts were dissolved in PC aiming at a concentration of $0.1 \mathrm{M}$ to target salt solubilityi.e., can we at all make electrolytes from these salts? Notably, $0.1 \mathrm{M}$ solutions in $\mathrm{PC}$ were easily prepared for the majority of salts under study, but $\mathrm{CaSO}_{4}$ and $\mathrm{Ca}(\mathrm{TMHD})_{2}$ presented poor solubilities, and therefore, their saturated electrolytes were used. While the viscosities of all electrolytes are relatively similar, their ionic conductivities differ greatly for the different salts under study (Figure 1a,b). The $\mathrm{Ca}(\mathrm{TMHD})_{2}$ - and $\mathrm{CaSO}_{4}$-based electrolytes show the lowest ion conductivities, mainly due to the poor salt solubility, while $\mathrm{Ca}(\mathrm{TFSI})_{2}$, $\mathrm{Ca}\left(\mathrm{BF}_{4}\right)_{2}$, and $\mathrm{Ca}(\mathrm{Tf})_{2}$ all perform better with their ion conductivities being 3 orders of magnitude higher (Figure 1b). This is consistent with the ease of ion-ion dissociation, facilitating solubility and creation of charge carriers. These results highlight one of the major issues in the development of new divalent-cation-based electrolytes: the salt solubility and the need for new highly dissociating salts. 
Turning to the role of the electrolyte solvent, $0.1 \mathrm{M}$ $\mathrm{Ca}(\mathrm{TFSI})_{2}$ electrolytes were studied (Figure 1c,d). It appears that the ion conductivity and the ability to dissolve Ca-salt both follow the solvent donor number (Table S1); highest for DMF and lowest for PC. This trend agrees well with the computed solubility of calcium salts in a wide variety of solvents. $^{32}$

Tentatively, salt solubility, and not viscosity, seems to be the determining factor for ion conductivity as we find, for example, one of the highest ion conductivities for the EC-based electrolyte (cf. Figure 1d) while being the most viscous electrolyte (Figure 1c). The THF- and glyme-based electrolytes show decreased ion conductivities as a function of temperature, an unusual behavior attributed to the presence and augmentation of strong ion pairing, as previously reported for Mg-glyme systems. ${ }^{33}$

Overall, the DMF-based electrolytes preliminarily seem to offer the best performance, and together with more standard PC- and EC-based electrolytes, maximum ionic conductivities are obtained for salt concentrations of $0.42-0.57 \mathrm{M}$ (Figure 2 ), after which a steep decrease is recorded, especially at lower temperatures. The maxima correspond to the lowest activation energies $\left(E_{\mathrm{a}}\right)$ in the VTF fits (Figure S6 and Table S3). Notably, these maxima are found at much lower salt concentrations than those for standard $\mathrm{Li}^{+}$and $\mathrm{Na}^{+}$conducting electrolytes, with maxima typically at 1.0-1.2 M. Therefore, as far as macroscopic properties (viscosity and ionic conductivity) are concerned, moderate salt concentrations (around 0.5 M), highly dissociating anions (such as TFSI or $\mathrm{BF}_{4}^{-}$), and solvents with high donor numbers (DMF, EC, or PC in that order) are required for Ca-battery electrolytes.

Ionicity. While viscosity, in general, limits ion motion in electrolytes, intermolecular and electrostatic interactions are also important as they affect both the solvation, i.e., nature and radius of the diffusing (cationic) species, and ion pairing, i.e., concentration of charge carriers. All of these interactions are taken into account in the ionicity of the electrolyte within the framework of the empirical Walden's rule. ${ }^{34}$ While originally formulated for infinitely diluted aqueous electrolytes with solvated ions of the same radius, it can be used to compare nonideal, nonaqueous electrolytes. In a Walden plot, the logarithm of the molar conductivity, $\Lambda$, is plotted against the fluidity, i.e., the inverse of the viscosity, $1 / \eta$, and most often an ideal (infinitely diluted) aqueous $\mathrm{KCl}$ solution is chosen as a reference system. ${ }^{35,36}$ Deviations below the ideal $\mathrm{KCl}$ line indicate that other actions than viscosity hinder the ionic motion, e.g., ion pairing.

The Walden plots for the $\mathrm{Ca}, \mathrm{Mg}$, and $\mathrm{Li}$ electrolytes show all data to fall below the ideal $\mathrm{KCl}$ line, and hence they are subject to ion pairing. The anion influence is clear as the ionicity (Figure $3 \mathrm{a}$ ) and the ion conductivity (Figure $1 \mathrm{~b}$ ) covary: $\mathrm{Ca}(\mathrm{TFSI})_{2}>\mathrm{Ca}\left(\mathrm{BF}_{4}\right)_{2}>\mathrm{Ca}(\mathrm{Tf})_{2}>\mathrm{Ca}(\mathrm{FOD})_{2}>$ $\mathrm{CaSO}_{4}>\mathrm{Ca}(\mathrm{TMHD})_{2}$, in clear agreement with how delocalized the negative charge is for the three former anions and the poor salt solubility and ion-ion dissociation for the three latter salts.

For the solvents, the ionicity of the electrolytes increases with increasing dielectric constant (Figure $3 \mathrm{~b}$ and Table S1): $\mathrm{EC}>\mathrm{PC}>\mathrm{gBL}>\mathrm{DMF}>$ triglyme $>$ diglyme $>\mathrm{DME}>\mathrm{THF}$. For THF and the glymes (incl. DME), the unusual behavior, illustrated by the negative slope in Figure $3 \mathrm{~b}$, can be attributed to their low dielectric constants and the formation of ionic aggregates. ${ }^{37}$ In contrast, the EC, PC, gBL, and DMF
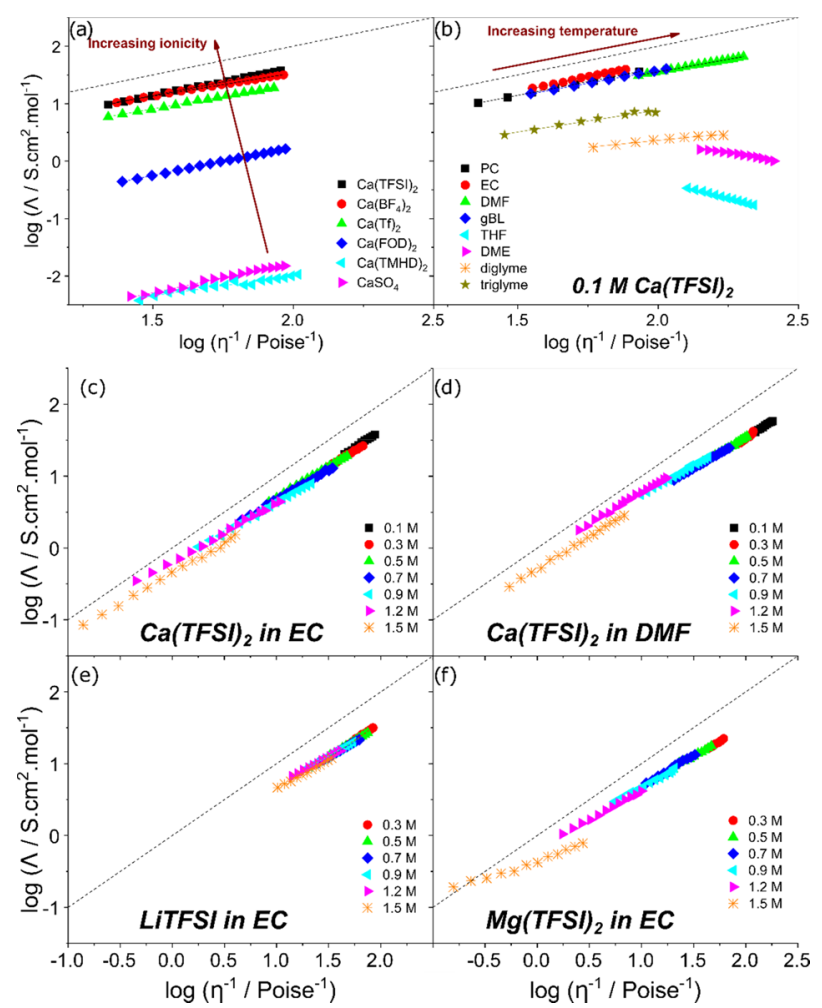

Figure 3. Walden plots of (a) different Ca-salts $(0.1 \mathrm{M})$ in PC, (b) $0.1 \mathrm{M} \mathrm{Ca}(\mathrm{TFSI})_{2}$ in different solvents and 0.1 to $1.5 \mathrm{M}$ (c) $\mathrm{Ca}(\mathrm{TFSI})_{2}$ in EC, (d) Ca(TFSI) $)_{2}$ in DMF, (e) LiTFSI in EC, and (f) $\mathrm{Mg}(\mathrm{TFSI})_{2}$ in EC. The dashed line represents an aqueous $\mathrm{KCl}$ solution as a reference for an ideal, fully dissociated electrolyte.

electrolytes have data in close vicinity to the ideal $\mathrm{KCl}$ standard line, implying a high ion-ion dissociation degree. The Walden plot slopes are 1.01, 0.95, 0.90, and 0.87 for EC, $\mathrm{PC}, \mathrm{gBL}$, and DMF, respectively, which shows that while the DMF electrolytes have the highest ion conductivities and lowest viscosities, they do seem slightly less dissociated than the gBL-, EC-, and even PC-based electrolytes.

Increasing the salt concentration results in very slight shifts toward the ideal $\mathrm{KCl}$ line and decreased slopes for both EC and DMF electrolytes (Figure $3 c-f)$. This is clearly observed for $\mathrm{Ca}(\mathrm{TFSI})_{2}$ and $\mathrm{Mg}(\mathrm{TFSI})_{2}$ but is much subtler for the LiTFSI electrolytes. It can be understood in terms of ionicity as increasing salt concentration for divalent cation electrolytes promotes extensive ion-ion interactions.

In contrast to the macroscopic view on electrolyte performance presented in the previous section, ionicity is a more local criterion, and an electrolyte with a high dielectric constant shows a better performance: $\mathrm{EC}>\mathrm{PC}>\mathrm{gBL}>\mathrm{DMF}$. Therefore, there is a clear discrepancy between the micro- and macroscopic points of view. To understand this discrepancy better, the molecular interactions and speciation were further investigated by vibrational spectroscopy.

Cation-Anion and Cation-Solvent Interactions. As the cation-solvent interactions compete with the cationanion interactions, we turn to vibrational spectroscopy to assess the local coordination in more detail. Starting with infrared spectroscopy, the very intense IR absorption band of the carbonyl $\mathrm{C}=\mathrm{O}$ stretching mode should be an interesting probe for EC, PC, and DMF as solvents. However, for cyclic carbonates, multiple mechanisms prevent any straightforward analysis. The fundamental stretching frequency of $\mathrm{C}=\mathrm{O}\left(\nu_{2}\right)$ 
at $1793 \mathrm{~cm}^{-1}$ couples strongly with the first overtone of the skeletal breathing of the ring $\left(2 \nu_{7}\right)$ and produces an intense band at $1767 \mathrm{~cm}^{-1}$; a Fermi resonance phenomenon (Figure 4). ${ }^{38}$ Upon coordination with a cation, these bands can, thus,

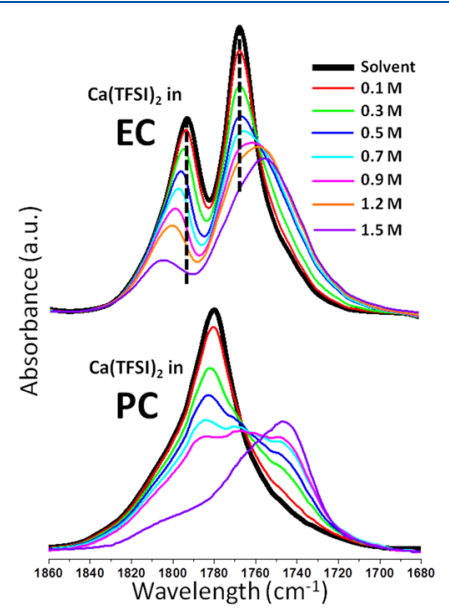

Figure 4. Carbonyl stretching region IR spectra of $\mathrm{Ca}(\mathrm{TFSI})_{2}$ in ECand PC-based electrolytes as a function of salt concentrations.

shift due to different mechanisms: losing the Fermi coupling condition would return the mode to its "unperturbed" frequency (gas-phase $\mathrm{IR}^{39}$ ca. $1870 \mathrm{~cm}^{-1}$, upward shift), decreased electron density of the $\mathrm{C}=\mathrm{O}$ bond (downward shift), and/or reduced intensity, and possibly a shift, of the $2 \nu_{7}$ overtone band due to the lack of Fermi resonance (upward shift). This complex combination of mechanisms prevents any unambiguous use of the carbonyl region.

Instead, the out-of-phase wagging of the $\mathrm{CH}_{2}$ groups $\left(\nu_{15}\right.$, $1390 \mathrm{~cm}^{-1}$ ) and the fundamental skeletal breathing of the ring $\left(\nu_{7}, 892 \mathrm{~cm}^{-1}\right)$ are used, and they both shift to higher wavenumbers as the Ca-salt concentration increases (Figure S7a). At 1.5 M, these "free" solvent bands are almost gone, suggesting that almost all ECs are coordinated by the $\mathrm{Ca}^{2+}$ cations. As compared to Li-salt-based electrolytes, where free EC is found even at $3 \mathrm{M}^{35}$ the $\mathrm{Ca}^{2+}$ cations are indeed expected to have larger first solvation shells.

The carbonyl region of the IR spectra of PC-based electrolytes is laden with the same problems as those for EC, but with the additional disadvantage that the lower symmetry of the PC produces, in general, broader bands. ${ }^{36}$ For the PC electrolytes, we indeed discern that all of the same modes are affected by $\mathrm{Ca}^{2+}$ coordination, but the shifts are not sufficiently large to allow us to correctly determine the contributions from free and coordinated PC, respectively.

In the IR spectra of DMF electrolytes (Figure 5), the $\mathrm{C}=\mathrm{O}$ stretching mode gets clearly shifted toward lower wavenumbers upon coordination by $\mathrm{Li}^{+}, \mathrm{Mg}^{2+}$, or $\mathrm{Ca}^{2+}$. However, the $\delta \mathrm{O}=\mathrm{C}-\mathrm{N}$ vibration at $658 \mathrm{~cm}^{-1}$ is a better option to analyze the cation-DMF interaction, with a significantly larger shift obtained for the $\mathrm{Mg}^{2+}$-containing electrolytes, attributed to the more polarizing character of the magnesium cation, resulting in a tighter first solvation shell. Significant differences in terms of solvation shell dynamics and desolvation energies are, thus, expected between the $\mathrm{Mg}-, \mathrm{Ca}-$, and $\mathrm{Li}$-based electrolytes.

Ohashi et al. recently reported that formamide coordinates $\mathrm{Ca}^{2+}$ cations only through the oxygen atom, ${ }^{40}$ but the nitrogen of the amide group might also take part in the cation

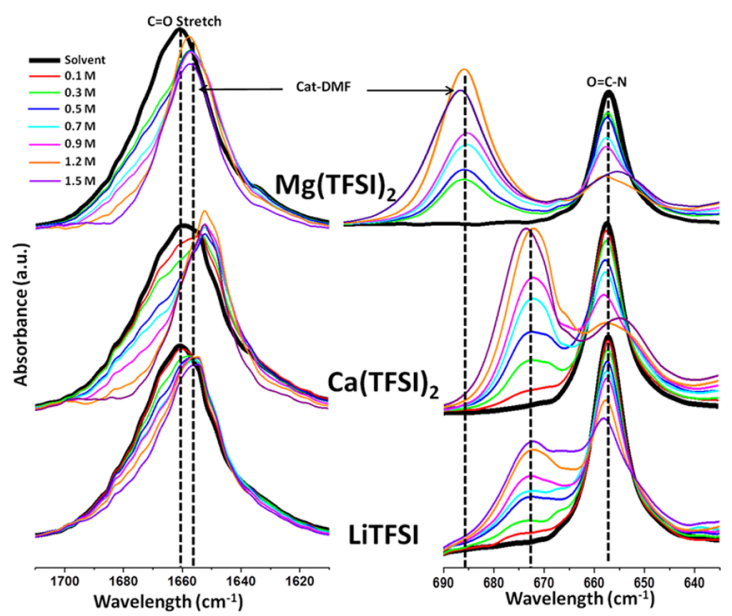

Figure 5. IR spectra of DMF-based electrolytes as a function of $\mathrm{Mg}(\mathrm{TFSI})_{2}, \mathrm{Ca}(\mathrm{TFSI})_{2}$, and LiTFSI salt concentrations.

coordination. ${ }^{41,42}$ As compared to formamide, the nitrogen atom in DMF has a higher electronic density due to the electron donor character of the methyl groups-further supported by computational studies showing that its electron lone-pair occupies a $\pi$ nonbonding molecular orbital, which also involves the methyl groups. ${ }^{43}$ The distinct $20 \mathrm{~cm}^{-1}$ shift of the symmetric bending of the $-\mathrm{CH}_{3}$ groups upon coordination by $\mathrm{Ca}^{2+}$ or $\mathrm{Mg}^{2+}$ points to a direct participation of the nitrogen atom in the cation solvation (Figure S7b).

For the cation solvation number determination, we turn to Raman spectroscopy and a few relatively intense bands for each solvent, which are minimally affected by other vibration modes but highly sensitive to cation coordination (Figure 6): ring breathing mode for $\mathrm{EC}$ (at $894 \mathrm{~cm}^{-1}$ ), $\gamma \mathrm{C}=\mathrm{O}$ for $\mathrm{PC}$ (sum of two bands at 706 and $712 \mathrm{~cm}^{-1}$ ), and $\delta \mathrm{O}=\mathrm{C}-\mathrm{N}$ for DMF (at $658 \mathrm{~cm}^{-1}$ ). At this point, we also include fluoroethylene carbonate (FEC) as a model solvent with a very low donor number, and the band analyzed is the ring breathing mode (at $905 \mathrm{~cm}^{-1}$ ).

For all regions, the free solvent band shifts toward higher wavenumbers upon cation coordination, and by deconvolution of the spectra (Figure S8), the solvation numbers (SNs) of the cations were calculated using eq 1

$$
\mathrm{SN}=\left(\frac{A_{\text {bound }}}{A_{\text {bound }}+\theta A_{\text {free }}}\right)\left(\frac{C_{\mathrm{s}}}{C_{\mathrm{Ca}^{2+}}}\right)
$$

where $C_{\mathrm{S}}$ and $C_{\mathrm{Ca}^{2+}}$ represent the molar concentrations of the solvent and Ca-salt, respectively. The parameter, $\theta$, is the ratio of the Raman activity of free and coordinated solvent molecules as obtained by density functional theory (DFT) calculations $\left(\theta=R A_{\text {coord. }} / R A_{\text {free }}\right)$.

Similarly, the number of TFSI anions coordinating each cation, as a measure of the contact ion-pair concentration, was calculated using eq 2

$$
\text { TFSI coordinated by } \mathrm{M}^{2+}=\left(\frac{2 A_{\text {coord. }}}{A_{\text {coord. }}+A_{\text {free }}}\right)
$$

This is derived from eq 1 and considers the 2:1 TFSI/Ca ${ }^{2+}$ relation and, furthermore, assumes that the TFSI all breathing mode (free at $740 \mathrm{~cm}^{-1}$ ) is equally Raman-active when "coordinated" $\left(\theta=1\right.$, confirmed for Li-based electrolytes $\left.{ }^{44}\right)$. 

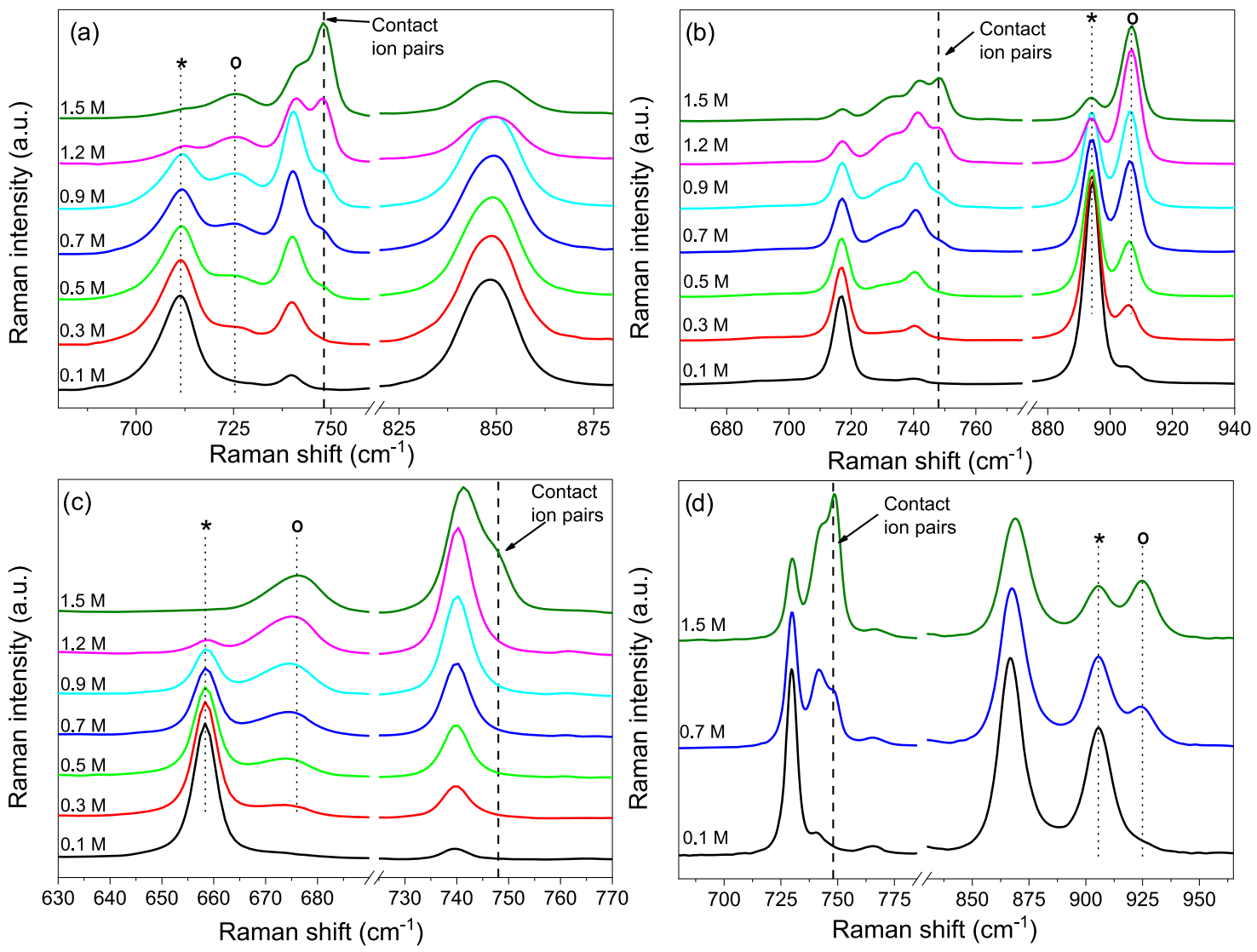

Figure 6. Raman spectra of Ca(TFSI) $)_{2}$ in (a) PC, (b) EC, (c) DMF, and (d) FEC, at different salt concentrations. * denotes free solvent, while ${ }^{\circ}$ denotes $\mathrm{Ca}^{2+}$-coordinated solvent. The band assigned to cation-anion contact ion pairs appears in all cases at $748 \mathrm{~cm}^{-1}$ and that of free TFSI at $740 \mathrm{~cm}^{-1}$.

The number of solvent molecules in the first solvation shell $\left(\mathrm{SN}_{\text {solvent }}\right)$ decreases upon increasing the salt concentration (Figure 7a), which can be explained by the displacement of solvent molecules by anions, thus forming contact ion pairs. The concentration threshold, when this process is triggered, is

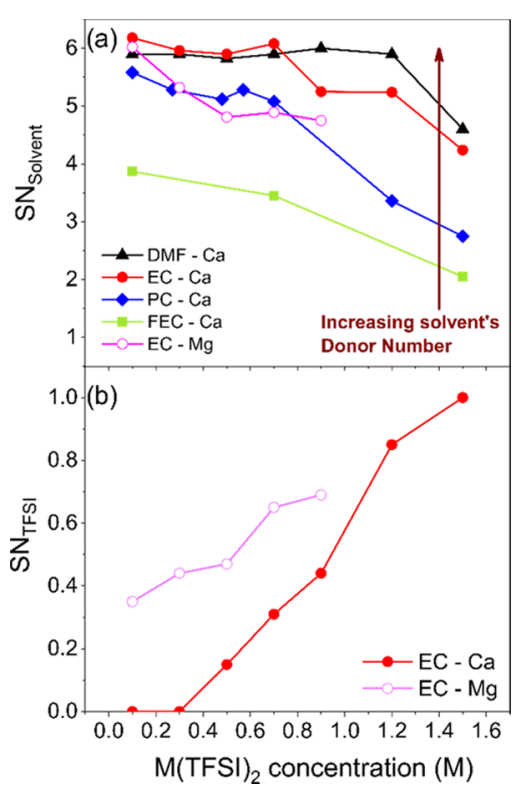

Figure 7. SN of (a) solvent and (b) TFSI as a function of M(TFSI) salt concentration $(\mathrm{M}=\mathrm{Ca}$ and $\mathrm{Mg})$. highly dependent on the electrolyte solvent (Figure 7a), where DMF is most resilient to be displaced, followed by EC, PC, and finally FEC-which correlates with their donor numbers (Table S1).

The formation of contact ion pairs can also be clearly observed in the Raman spectra of the electrolytes by the appearance of a band at $748 \mathrm{~cm}^{-1}$ attributed to $\mathrm{Ca}^{2+}-$ TFSI complexes (Figure 6). Indeed, DMF is proven to be a very good solvent as no contact ion pairs were detected below 1.2 $M$ salt concentration, while for carbonate solvents (EC and PC) they appeared already at $0.5 \mathrm{M}$.

The formation of contact ion pairs also heavily depends on the salt employed; as TFSI is flexible and its charge is highly delocalized, it is less prone to contact ion-pair formation and is, thus, preferred over other anions (such as $\mathrm{BF}_{4}^{-}$), which are involved in the solvation shell at lower concentrations (Figure S9). For Mg electrolytes, however, the polarizing character of $\mathrm{Mg}^{2+}$ promotes the formation of contact ion pairs even for 0.1 $\mathrm{M} \mathrm{Mg}(\mathrm{TFSI})_{2}$ in EC (Figure $7 \mathrm{~b}$ ).

While the formation of contact ion pairs is moderated by the solvent's donor numbers, we propose that its permittivity (dielectric constant) plays a major role in the formation of solvent-separated ion pairs. In the Raman spectra of DMF electrolytes (a low-polarity solvent), the band of free TFSI $\left(740 \mathrm{~cm}^{-1}\right)$ grows more asymmetric in the range from $0.3-1.2$ M. This asymmetry evidences a certain cation-anion interaction even if there is no direct contact. The presence of such solvent-separated ion pairs could, at least partially, explain why DMF-based electrolytes do not provide the 
highest ionicities (Figure 4b). On the other hand, the high permittivities of EC and PC effectively shield the cation charge, decreasing the tendency to form solvent-separated ion pairs, and hence, result in higher ionicities. Yet, as the donor numbers of EC and PC are lower, they are more easily displaced by the TFSI anions as the salt concentration increases, forming contact ion pairs and possibly higher aggregates.

We also observe that the total SN (solvent + anion) decreases as a function of salt concentration, and hence, each anion entering displaces more than one solvent molecule. If the coordination sites of the cation are to be constant, bidentate coordination can be expected by either TFSI or the solvent. For cyclic carbonates, bidentate coordination to $\mathrm{Li}^{+}$and $\mathrm{Na}^{+}$ has been proposed for highly concentrated electrolytes, ${ }^{45}$ and as the band for the coordinated solvent is actually composed of two contributions shifted by ca. $5 \mathrm{~cm}^{-1}$ (Figure S10), bidentate coordination could also be the case for $\mathrm{Ca}^{2+}$.

The evolution of the amount of free solvent molecules with salt concentration also appears to be solvent-dependent. For the PC- and DMF-based electrolytes almost no free solvent band can be detected (Figure 6a,c) for salt concentrations above $1.2 \mathrm{M}$, while they can still be detected for higher salt concentrations for both EC and FEC, most likely due to the bidentate coordination of the solvent in the first case and to the high degree of ion-pair formation in the latter. For $\mathrm{Mg}(\mathrm{TFSI})_{2}$ in EC, a larger free solvent feature was obtained as compared to the $\mathrm{Ca}$ system, in agreement with the higher degree of ion-pair formation. In all cases, the threshold concentration needed to reach the highly concentrated electrolyte domain is much lower for systems with divalent cations as compared to monovalent cation based electrolytes ( $>3 \mathrm{M}$ ), in agreement with the higher coordination number of $\mathrm{Ca}$ and $\mathrm{Mg}$ (typically $>6$ ) than that of Li (typically 4). ${ }^{12,16}$

Understanding the solvation structure of battery electrolytes is a crucial step in the quest for electrolyte optimization. Indeed, the formation of cation-anion pairs effectively diminishes the amount of charge carriers, and a cation in solution needs to get rid of its solvation shell before plating or insertion can take place at the anode and cathode, respectively. The ease with which the cation desolvates is related to its binding energy with other species. Binding energies were calculated for the $\mathrm{M}-\mathrm{X}$ complexes (Table S6), and much larger energies were obtained for the ion pairs; M-TFSI with 1162 and $1442 \mathrm{~kJ} \mathrm{~mol}^{-1}$ for $\mathrm{M}=\mathrm{Ca}$ and $\mathrm{Mg}$, respectively, as compared to the cation-solvent interactions; M-EC with 380 and $544 \mathrm{~kJ} \mathrm{~mol}^{-1}$ for $\mathrm{M}=\mathrm{Ca}$ or $\mathrm{Mg}$, respectively. Thus, as far as interfacial processes are concerned, Ca-based systems present prospects for better power performance than $\mathrm{Mg}$. For both systems, a solvation shell composed mainly of solvent molecules is preferred (absence of ion pairs), which can be achieved by using high donor number solvents and moderate salt concentrations.

\section{CONCLUSIONS}

Ca-based electrolytes were studied, and the influence of salt, concentration, and the solvent was investigated in terms of ionic conductivity, viscosity, ionicity, and solvation structure and in some cases compared with $\mathrm{Li}$ and $\mathrm{Mg}$ solutions. One of the main issues for further development of divalent-cationbased electrolytes, in general and also true for Ca batteries, is the salt solubility - resulting in only a few Ca-salts possible and only when combined with high-permittivity solvents. The degree of contact ion-pair formation and mono- vs bidentate coordination were both found to evolve with salt concentration and solvent donor number. The amount of free solvent molecules evolves accordingly, and divalent cation based electrolytes enter the domain of highly concentrated electrolytes at concentrations as low as $1.2 \mathrm{M}$. We found that a high donor number solvent, such as DMF, allows for both low viscosities, high ion conductivities, as well as few contact ion pairs (although solvent-separated ion pairs can be envisaged, resulting in low ionicity). The lower probability for contact ion pairs, together with the lower interaction energies within their solvation shell, is fundamentally promising for better kinetics of metal plating and cation insertion.

\section{ASSOCIATED CONTENT}

\section{Supporting Information}

The Supporting Information is available free of charge at https://pubs.acs.org/doi/10.1021/acs.jpcc.9b07308.

Physicochemical properties of salts, solvents, and calcium electrolytes; Vogel-Tammann-Fulcher (VTF) parameters of viscosities and conductivities; infrared and Raman spectra of calcium electrolytes; deconvolution of Raman spectra; interaction/binding energies; Raman parameters for fitting (PDF)

\section{AUTHOR INFORMATION}

\section{Corresponding Authors}

*E-mail: patrik.johansson@chalmers.se (P.J.).

*E-mail: aponrouch@icmab.es (A.P.).

ORCID $\odot$

J. D. Forero-Saboya: 0000-0002-3403-6066

P. Johansson: 0000-0002-9907-117X

A. Ponrouch: 0000-0002-8232-6324

Notes

The authors declare no competing financial interest.

\section{ACKNOWLEDGMENTS}

Funding from the European Union's Horizon 2020 research and innovation program H2020 is acknowledged: European Research Council (ERC-2016-STG, CAMBAT grant agreement No. 715087), FETOPEN-1-2016-2017 (CARBAT, grant agreement No. 766617), and H2020-MSCA-COFUND-2016 (DOC-FAM, grant agreement No. 754397). A.P. is grateful to the Spanish Ministry for Economy, Industry and Competitiveness Severo Ochoa Program for Centers of Excellence in R\&D (SEV-2015-0496). P.J. acknowledges financial support from the Swedish Energy Agency (contract \#37671-1, Next Generation Batteries) and Chalmers Battery Initiative, part of the profile Materials for Energy Applications jointly managed by the Areas of Advance Materials Science and Energy at the Chalmers University of Technology. The stimulating discussions within the ALISTORE-ERI network are also highly appreciated. This work was done within the framework of the Doctoral Degree Program in Materials Science by the Universitat Autònoma de Barcelona. We are grateful to Nicolas Monti for the elaboration of the TOC graphical abstract.

\section{REFERENCES}

(1) $\mathrm{Xu}, \mathrm{K}$. Nonaqueous Liquid Electrolytes for Lithium-Based Rechargeable Batteries. Chem. Rev. 2004, 104, 4303-4418. 
(2) Li, H.; Zhou, H. Enhancing the Performances of Li-Ion Batteries by Carbon-Coating: Present and Future. Chem. Commun. 2012, 48, 1201-1217.

(3) Yoo, H. D.; Shterenberg, I.; Gofer, Y.; Gershinsky, G.; Pour, N.; Aurbach, D. Mg Rechargeable Batteries: An on-Going Challenge. Energy Environ. Sci. 2013, 6, 2265-2279.

(4) Canepa, P.; Sai Gautam, G.; Hannah, D. C.; Malik, R.; Liu, M.; Gallagher, K. G.; Persson, K. A.; Ceder, G. Odyssey of Multivalent Cathode Materials: Open Questions and Future Challenges. Chem. Rev. 2017, 117, 4287-4341.

(5) Selis, S. M.; Wondowski, J. P.; Justus, R. F. A High-Rate, HighEnergy Thermal Battery System. J. Electrochem. Soc. 1964, 111, 6-13.

(6) Arroyo-de Dompablo, M. E.; Ponrouch, A.; Johansson, P.; Palacín, M. R. Achievements, Challenges, and Prospects of Calcium Batteries Chem. Rev. 2019, DOI: 10.1021/acs.chemrev.9b00339.

(7) Staniewicz, R. J. A Study of the Calcium-Thionyl Chloride Electrochemical System. J. Electrochem. Soc. 1980, 127, 782-789.

(8) Muldoon, J.; Bucur, C. B.; Gregory, T. Quest for Nonaqueous Multivalent Secondary Batteries: Magnesium and Beyond. Chem. Rev. 2014, 114, 11683-11720.

(9) Aurbach, D.; Skaletsky, R.; Gofer, Y. The Electrochemical Behavior of Calcium Electrodes in a Few Organic Electrolytes. J. Electrochem. Soc. 1991, 138, 3536-3545.

(10) Lu, Z.; Schechter, A.; Moshkovich, M.; Aurbach, D. On the Electrochemical Behavior of Magnesium Electrodes in Polar Aprotic Electrolyte Solutions. J. Electroanal. Chem. 1999, 466, 203-217.

(11) Ponrouch, A.; Frontera, C.; Bardé, F.; Palacín, M. R. Towards a Calcium-Based Rechargeable Battery. Nat. Mater. 2016, 15, 169.

(12) Wang, D.; Gao, X.; Chen, Y.; Jin, L.; Kuss, C.; Bruce, P. G. Plating and Stripping Calcium in an Organic electrolyte. Nat. Mater. 2018, 17, 16.

(13) Son, S.-B.; Gao, T.; Harvey, S. P.; Steirer, K. X.; Stokes, A.; Norman, A.; Wang, C.; Cresce, A.; Xu, K.; Ban, C. An Artificial Interphase Enables Reversible Magnesium Chemistry in Carbonate Electrolytes. Nat. Chem. 2018, 10, 532-539.

(14) Ponrouch, A.; Palacin, M. R. On the Road toward CalciumBased Batteries. Curr. Opin. Electrochem. 2018, 9, 1-7.

(15) Ponrouch, A.; Bitenc, J.; Dominko, R.; Lindahl, N.; Johansson, P.; Palacin, M. R. Multivalent Rechargeable Batteries. Energy Storage Mater. 2019, 20, 253-262.

(16) Tchitchekova, D. S.; Monti, D.; Johansson, P.; Bardé, F.; Randon-Vitanova, A.; Palacín, M. R.; Ponrouch, A. On the Reliability of Half-Cell Tests for Monovalent $\left(\mathrm{Li}^{+}, \mathrm{Na}^{+}\right)$and Divalent $\left(\mathrm{Mg}^{2+}\right.$, $\mathrm{Ca}^{2+}$ ) Cation Based Batteries. J. Electrochem. Soc. 2017, 164, A1384A1392.

(17) Okoshi, M.; Yamada, Y.; Komaba, S.; Yamada, A.; Nakai, H. Theoretical Analysis of Interactions between Potassium Ions and Organic Electrolyte Solvents: A Comparison with Lithium, Sodium, and Magnesium Ions. J. Electrochem. Soc. 2017, 164, A54-A60.

(18) Xu, K.; von Cresce, A.; Lee, U. Differentiating Contributions to "Ion Transfer" Barrier from Interphasial Resistance and $\mathrm{Li}^{+}$Desolvation at Electrolyte/Graphite Interface. Langmuir 2010, 26, 1153811543.

(19) $\mathrm{Xu}, \mathrm{K}$. Electrolytes and Interphases in Li-Ion Batteries and Beyond. Chem. Rev. 2014, 114, 11503-11618.

(20) Gauthier, M.; et al. Electrode-Electrolyte Interface in Li-Ion Batteries: Current Understanding and New Insights. J. Phys. Chem. Lett. 2015, 6, 4653-4672.

(21) Minato, T.; Abe, T. Surface and Interface Sciences of Li-Ion Batteries: -Research Progress in Electrode-Electrolyte Interface. Prog. Surf. Sci. 2017, 92, 240-280.

(22) Ahlrichs, R.; Bär, M.; Häser, M.; Horn, H.; Kölmel, C. Electronic Structure Calculations on Workstation Computers: The Program System Turbomole. Chem. Phys. Lett. 1989, 162, 165-169.

(23) Larsen, A. H.; et al. The Atomic Simulation Environment-a Python Library for Working with Atoms. J. Phys.: Condens. Matter 2017, 29, No. 273002.
(24) Goedecker, S. Minima Hopping: An Efficient Search Method for the Global Minimum of the Potential Energy Surface of Complex Molecular Systems. J Chem. Phys. 2004, 120, 9911-9917.

(25) Schäfer, A.; Horn, H.; Ahlrichs, R. Fully Optimized Contracted Gaussian Basis Sets for Atoms Li to Kr. J. Chem. Phys. 1992, 97, 2571-2577.

(26) Becke, A. D. Density-Functional Exchange-Energy Approximation with Correct Asymptotic Behavior. Phys. Rev. A 1988, 38, 3098-3100.

(27) Zhao, Y.; Truhlar, D. G. The M06 Suite of Density Functionals for Main Group Thermochemistry, Thermochemical Kinetics, Noncovalent Interactions, Excited States, and Transition Elements: Two New Functionals and Systematic Testing of Four M06-Class Functionals and 12 Other Functionals. Theor. Chem. Acc. 2008, 120, 215-241.

(28) Hehre, W. J.; Ditchfield, R.; Pople, J. A. Self-Consistent Molecular Orbital Methods. XII. Further Extensions of GaussianType Basis Sets for Use in Molecular Orbital Studies of Organic Molecules. J. Chem. Phys. 1972, 56, 2257-2261.

(29) Francl, M. M.; Pietro, W. J.; Hehre, W. J.; Binkley, J. S.; Gordon, M. S.; DeFrees, D. J.; Pople, J. A. Self-Consistent Molecular Orbital Methods. XXIII. A Polarization-Type Basis Set for SecondRow Elements. J.Chem. Phys. 1982, 77, 3654-3665.

(30) Bochevarov, A. D.; Harder, E.; Hughes, T. F.; Greenwood, J. R.; Braden, D. A.; Philipp, D. M.; Rinaldo, D.; Halls, M. D.; Zhang, J.; Friesner, R. A. Jaguar: A High-Performance Quantum Chemistry Software Program with Strengths in Life and Materials Sciences. Int. J. Quantum Chem. 2013, 113, 2110-2142.

(31) Jaguar, version 9.1; Schrödinger, LLC: New York, 2019.

(32) Araujo, R. B.; Johansson, P., Manuscript in Preparation.

(33) Samuel, D.; Steinhauser, C.; Smith, J. G.; Kaufman, A.; Radin, M. D.; Naruse, J.; Hiramatsu, H.; Siegel, D. J. Ion Pairing and Diffusion in Magnesium Electrolytes Based on Magnesium Borohydride. ACS Appl. Mater. Interfaces 2017, 9, 43755-43766.

(34) Walden, P. Über Organische Lôsungs- Und Ionisiernngsmittel. III. Teil: Innere Reibnng Und Deren Zusammenhang Mit Dem Leitvermögen. Z. Phys. Chem. 1906, 55, 207-249.

(35) Seo, D. M.; Reininger, S.; Kutcher, M.; Redmond, K.; Euler, W. B.; Lucht, B. L. Role of Mixed Solvation and Ion Pairing in the Solution Structure of Lithium Ion Battery Electrolytes. J. Phys. Chem. C 2015, 119, 14038-14046.

(36) Jankowski, P.; Grzegorzewska, K.; Szabłowska, A.; Piszcz, M.; Dranka, M.; Żukowska, G. Z.; Kalita, M. Role of Propylene Carbonate Chirality on Physicochemical Properties of the Corresponding Ion Conductors. Electrochim. Acta 2015, 175, 240-246.

(37) Schreiner, C.; Zugmann, S.; Hartl, R.; Gores, H. J. Fractional Walden Rule for Ionic Liquids: Examples from Recent Measurements and a Critique of the So-Called Ideal $\mathrm{KCl}$ Line for the Walden Plot. J. Chem. Eng. Data 2010, 55, 1784-1788.

(38) Fortunato, B.; Mirone, P.; Fini, G. Infrared and Raman Spectra and Vibrational Assignment of Ethylene Carbonate. Spectrochim. Acta, Part A 1971, 27, 1917-1927.

(39) Angell, C. L. The Infra-Red Spectra and Structure of Ethylene Carbonate. Trans. Faraday Soc. 1956, 52, 1178-1183.

(40) Ohashi, K.; Hikiishi, N.; Takeshita, H. Infrared Spectroscopic and Computational Studies on Formamide Solutions of $\mathrm{Ca} 2+$. Vibrational Frequencies of Formamide and Modes of Coordination to $\mathrm{Ca}^{2+}$. Spectrochim. Acta, Part A 2019, 206, 112-119.

(41) Bukowska, J. Raman and Infrared Studies of Interactions between Amides and Ions. J. Mol. Struct. 1983, 98, 1-10.

(42) Bukowska, J.; Miaskiewicz, K. Infrared, Raman, and Cndo Studies of the Effect of Ions on the Electron Density Distribution in Formamide. J. Mol. Struct. 1981, 74, 1-10.

(43) Shastri, A.; Das, A. K.; Krishnakumar, S.; Singh, P. J.; Sekhar, B. N. R. Spectroscopy of N,N-Dimethylformamide in the VUV and IR Regions: Experimental and Computational Studies. J. Chem.Phys. 2017, 147, No. 224305. 
(44) Lassègues, J.-C.; Grondin, J.; Aupetit, C.; Johansson, P. Spectroscopic Identification of the Lithium Ion Transporting Species in LiTFSI-Doped Ionic Liquids. J. Phys. Chem. A 2009, 113, 305-314.

(45) Flores, E.; Åvall, G.; Jeschke, S.; Johansson, P. Solvation Structure in Dilute to Highly Concentrated Electrolytes for LithiumIon and Sodium-Ion Batteries. Electrochim. Acta 2017, 233, 134-141. 